\title{
PERANCANGAN PROTOTYPE VOIP MENGGUNAKAN OPENSOURCE ASTERISK DAN VIRTUAL MACHINE ENGINE GOOGLE CLOUD PADA PERUSAHAAN XYZ
}

\author{
Sandra Nurtaminingsih \\ Teknik Informatika dan Komputer, Politeknik Negeri Jakarta \\ sandra.nurtaminingsih.tik16@mhsw.pnj.ac.id
}

\begin{abstract}
Abstrak
Komunikasi merupakan hal yang penting bagi semua manusia termasuk kegiatan dalam sekolah untuk saling bertukar informasi. VoIP atau dikenal juga dengan IP Telephony merupakan teknologi yang memanfaatkan teknologi internet untuk melakukan percakapan suara jarak jauh. Dengan adanya media internet, data suara dikonversi menjadi kode digital dan kemudian dikirim sebagai paket-paket data di dalam jaringan internet. Pada penelitian ini implementasi jaringan VoIP akan dilakukan di perusahaan XYZ untuk memudahkan berkomunikasi menggunakan jaringan lokal yang ada. Sistem VoIP yang akan dibuat prototypenya yaitu akan menggunakan Asterisk sebagai server yang nantinya akan di lakukan pada Virtual Machine Engine Google Cloud. Setiap user dapat mendaftarkan teleponnya secara mudah dengan adanya sistem ini.
\end{abstract}

Kata kunci: Asterisk, Google Cloud, VoIP

\section{Pendahuluan}

Komunikasi merupakan hal yang penting bagi semua manusia. Untuk mencapai sebuah tujuan bersama dibutuhkan sebuah komunikasi yang baik. Seiring berkembangnya waktu, semua komunikasi dapat berjalan dengan baik dan mudah. Hal itu tentunya didukung oleh majunya dunia digital di era ini. Khususnya komunikasi menggunakan internet menjadi pilihan yang paling utama saat ini.

Salah satunya yaitu komunikasi dengan memanfaatkan teknologi jaringan Voice over Internet Protocol (VoIP). VoIP atau dikenal juga dengan IP Telephony merupakan teknologi yang memanfaatkan teknologi internet untuk melakukan percakapan suara jarak jauh. Dengan adanya media internet, data suara dikonversi menjadi kode digital dan kemudian dikirim sebagai paket-paket data di dalam jaringan internet.

Penggunaan telepon berbasis VoIP memiliki banyak keuntungan seperti biaya yang digunakan dalam berkomunikasi lebih rendah daripada melalui jaringan telepon biasa (PSTN). Untuk saat ini, pada perusahaan XYZ masih menggunakan jaringan komunikasi VoIP yang sepenuhnya ditangani oleh vendor. Berbagai vendor memiliki penawaran dengan harga yang kompetitif. Begitu juga pelayanan yang ditawarkan cukup beragam.

Tingginya biaya komunikasi VoIP menggunakan vendor saat ini, menjadi alasan mendasar ingin adanya perancangan VOIP yang dapat dikelola semuanya oleh perusahaan XYZ sendiri. Hal itu yang kemudian menjadi tugas penulis agar dapat membuat VOIP berbasis Asterisk. Penggunaan Asterisk dapat menekan biaya operasional yang jauh lebih murah, reliabilitas lebih tinggi, penggunaan yang mudah, dan interoperabilitas perangkat yang telah mendukung banyak hardware.

\section{Tinjuan Pustaka}

Sistem komunikasi VOIP menggunakan opensource Asterisk dan Virtual Machine Engine Google Cloud memiliki kelebihan yaitu lebih hemat dan efisien untuk sebuah perusahaan. Hal itu berdasarkan beberapa penelitian sebelumnya yaitu sebagai berikut: 
1. Husnul Khuluq, Makinun Amin, Mohamad Hariyadi, Muhamad Afif Effindi (2016) dengan judul penelitian "Implementasi Voip (Voice Over Internet Protocol) Server Berbasis Raspberry Pi Sebagai Media Komunikasi" Penelitian ini melakukan pengintegrasian Raspberry Pi dengan aplikasi Raspian Jessie dan FreePBX dan menggunakan sistem operasi Linux sebagai pondasi utama. FreePBX di Raspberry Pi bertujuan untuk layanan telepon berbasis IP lalu menghubungkan aplikasi VoIP mobile dan PC ke Raspberry Pi yang yang berfungsi sebagai server VoIP, serta melakukan pengujian terhadap kinerja server layanan VoIP pada saat melakukan panggilan.

2. Welaspen Yunarti, Rusdianto Roestam (2016) dengan judul penelitian "Analisis dan Rancang Bangun Jaringan Komunikasi VOIP Dengan Server Briker Pada SMKN 1 Tanjung Jabung Timur". Untuk mencapai komunikasi antar bagian atau antar siswa dapat terjadi seefisien dan ekonomis mungkin di lingkungan SMKN 1 Tanjung Jabung Timur. Penelitian dilakukan dengan memanfaatkan penggabungan teknologi VoIP menggunakan Briker dan teknologi chatting menggunakan Linphone.

3. Mohammad Risnandar, Ade Hendri Hendrawan, Bayu Adhi Prakosha, Arief Goeritno (2016). Penelitian ini menggunakan Briker Versi 1.4 dalam mengimplementasikan VoIP berbasis Session Initiation Protocol (SIP) yang bertujuan untuk mengukur Quality of Services Jaringan Komputer suatu Fakultas. Penelitian yang dilakukan dengan bantuan Briker ini memantau paket data yang dikirim dan diterima oleh pengguna telepon lalu menyaring paket data yang berhubungan dengan protokol SIP.

\section{Metode Penelitian}

\section{Diagram alur penelitian}

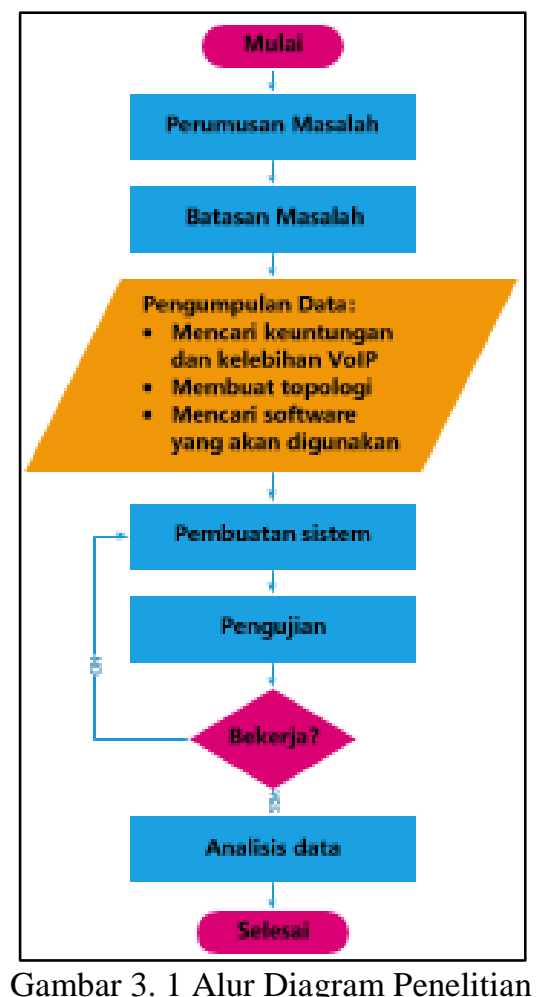

Penelitian diawali dengan merumuskan masalah yang ada pada perusahaan XYZ, masalah tersebut mencakup VoIP yang digunakan pada perusahaan XYZ. Selanjutnya menentukan batasan masalah yang nantinya berfungsi untuk memudahkan perancangan sistem selama penelitian. Tahap ketiga yaitu mengumpulkan data-data yang nantinya akan digunakan sebagai acuan dalam membangun sistem ini. Hal itu meliputi mencari kekurangan dan kelebihan jaringan komunikasi VoIP, membuat topologi yang akan dipakai, mencari informasi tentang software yang paling cocok dengan masalah yang ada. Setelah data tersebut terkumpul maka dilakukan pembuatan sistem seperti melakukan instalasi software, mengkonfigurasi server, dan mengkonfigurasi user. Hal yang paling penting berikutnya yaitu melakukan pengujian sistem. Ketika sistem tidak bekerja dengan baik, maka harus melakukan pengulangan pada pembuatan sistem. Jika sistem berjalan dengan baik maka dilakukan analisis data dan penelitian selesai. 


\section{Topologi Jaringan}

Perancangan ini dilakukan berdasarkan pada topologi yang telah diterapkan oleh departemen IT perusahaan XYZ, berikut adalah topologi dari perancangan ini:

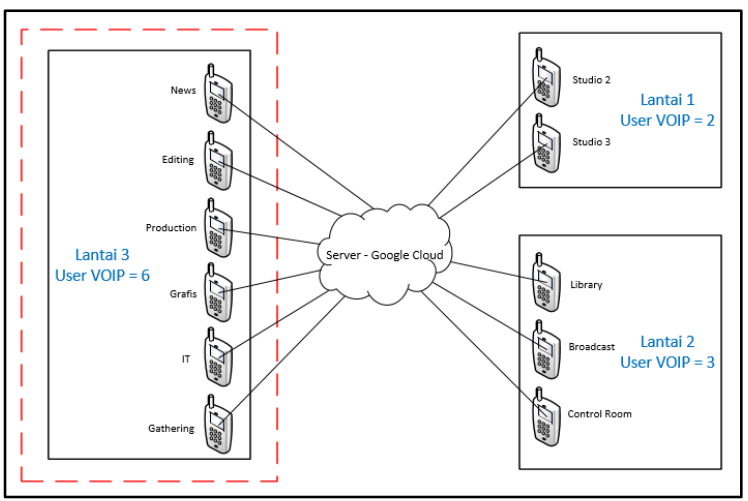

Gambar 3. 2 Topologi Jaringan

Pada gambar diatas merupakan topologi jaringan pada setiap lantai di perusahaan XYZ yang mana setiap divisi memiliki satu smartphone yang berfungsi untuk melakukan atau menerima panggilan dengan VOIP. Agar dapat saling terhubung, setiap divisi terdaftar pada server yang berada pada Google Cloud.

Sistem yang akan dibangun kali ini akan dirancang terlebih dahulu untuk percobaan pada lantai 3 perusahaan XYZ, seperti pada gambar di dalam kotak merah. Dimana pada lantai 3 memiliki 6 divisi yang akan di uji coba nantinya. Disivi tersebut terdiri dari ruang news, ruang editing, ruang production, ruang grafis, ruang IT dan juga ruang gathering.

\section{Hasil dan Pembahasan}

Pada uraian di bawah ini akan dijelaskan serangkaian kegiatan yang bersangkutan dengan rancang bangun VoIP hingga user dapat saling berkomunikasi. Dimulai dari pembuatan topologi IP phone, pembuatan server VoIP, konfigurasi server, dan memberikan akses kepada user agar dapat terdaftar pada sistem.

\section{Perancangan sistem}

Rancang bangun VoIP yang dibuat adalah dengan memanfaatkan Google Cloud sebagai server dan penggunaan smartphone dengan jaringan internet untuk mengakses server VoIP. Server yang dibuat berbasis Asterisk dikarenakan Astersik merupakan software yang bersifat open source, biaya yang lebih terjangkau dan penggunaan yang mudah. Setelah server di virtual machine selesai dibuat maka berlanjut generate karena dari Google Cloud untuk melakukan koneksi ke server yang dibuat harus membuat $\mathrm{SSH}$ key sendiri dan menghasilkan public SSH key untuk third-party.

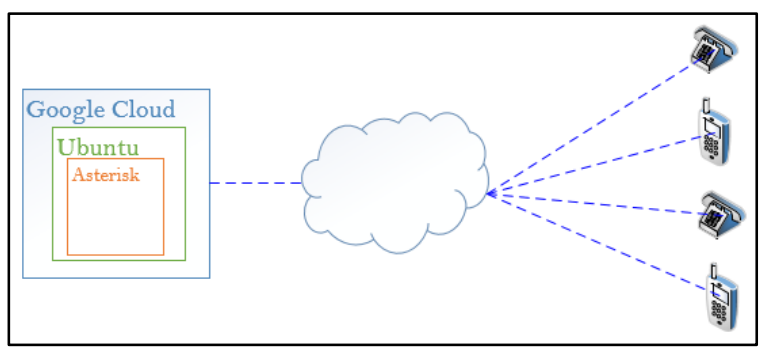

Gambar 4. 1 Perancangan sistem

\section{Perancangan pada Sisi Server}

Perancangan pada sisi server dilakukan menggunakan server virtual yang dibuat pada Google Cloud. Google Cloud digunakan karena instalasinya sederhana dan dapat dikendalikan dari jauh dimanapun dan kapanpun. Sistem operasi yang digunakan untuk dijadikan server adalah sistem operasi Ubuntu. Pada proses perancangan pada sisi server, ada beberapa tahap perancangan yang yang harus dilakukan. Tahapan-tahapan tersebut seperti pada gambar dibawah ini. 


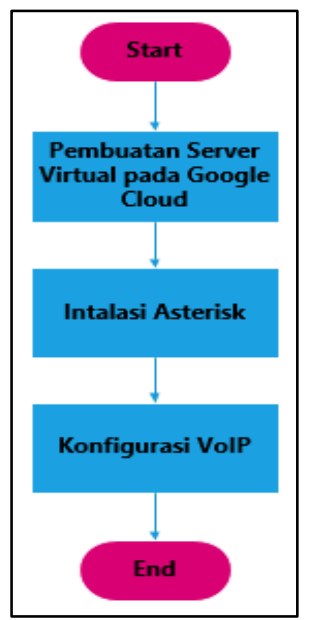

Gambar 4. 2 Perancangan pada server

Proses pertama yaitu melakukan pembuatan server virtual pada Google Cloud. Proses kedua yaitu instalasi software Asterisk. Proses ketiga konfigurasi server VoIP dan konfigurasi user untuk mendapatkan hak panggilan pada account SIP agar tidak sembarangan orang yang dihubungi.

\section{Perancangan pada Sisi User}

Pada proses perancangan pada sisi client, ada beberapa tahap perancangan yang harus dilakukan. Perancangan yang dilakukan pada sisi user yaitu pertama kali melakukan instalasi software voip gratis MizuDroid. Proses kedua yaitu melakukan registrasi agar terhubung pada server VoIP. Jika registrasi berhasil maka proses dial dapat berlangsung. Tetapi jika proses registrasi tidak berhasil maka melakukan pengecekan konfigurasi lagi. Tahapan-tahapan tersebut dapat dilihat pada flowchart dibawah ini.

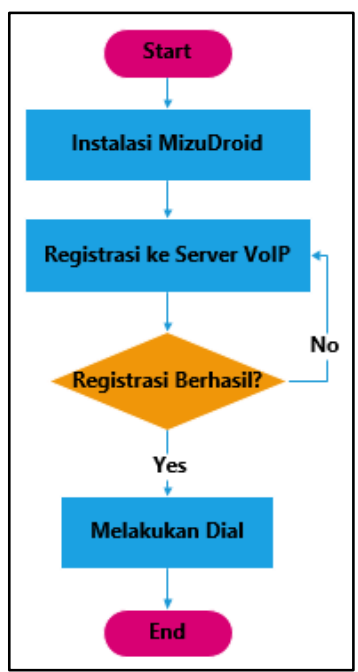

Gambar 4. 3 Perancangan pada user

\section{Konfigurasi User}

Konfigurasi user bertujuan untuk mendaftarkan pengguna agar nantinya dapat menggunakan layanan VoIP. Dari hasil konfigurasi yang ada, berikut ini adalah keseluruhan dari konfigurasi user 6 divisi pada lantai 3 perusahaan XYZ:

Tabel 4. 1 Tabel user terdaftar

\begin{tabular}{|c|c|c|c|c|}
\hline context & type & username & secret & host \\
\hline cnn & friend & news & 90001 & dynamic \\
\hline cnn & friend & editing & 90002 & dynamic \\
\hline cnn & friend & production & 90003 & dynamic \\
\hline cnn & friend & grafis & 90004 & dynamic \\
\hline cnn & friend & it & 90005 & dynamic \\
\hline cnn & friend & gathering & 90006 & dynamic \\
\hline
\end{tabular}

\section{Analisis Pengujian} Pengujian user yang telah terdaftar

Untuk mengecek apakah ada user yang terdaftar dan siapa saja yang terdaftar maka dapat menggunakan sintaks sip show users. Maka akan ada data yang ditampilkan seperti nama user yang terdaftar, password user, context, status ACL dan forceport nya. Data hasil dari konfigurasi yang dilakukan sebelumnya adalah sebagai berikut:

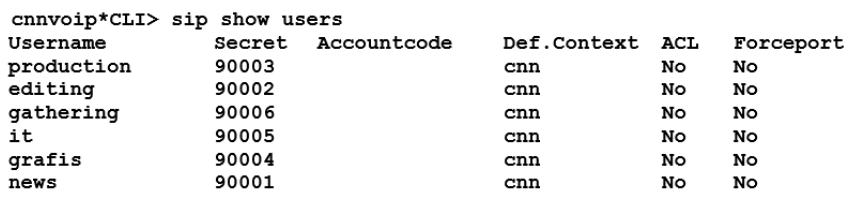

Gambar 5. 1 Pengecekan user terdaftar 


\section{Pengujian keberhasilan panggilan pada beberapa kondisi}

Pengujian dilakukan menggunakan 3 kondisi yang diambil dari kondisi yang kemungkinan akan sering terjadi ketika komunikasi berlangsung. Tiga kondisi tersebut yaitu:

\section{A. Kondisi Pertama}

User yang akan melakukan uji coba yaitu News, Editing, dan Production. Pengujian ini berlangsung dengan melakukan panggilan antara user News dan user Editing. Setelah beberapa saat akan ada telepon masuk dari user Production ke user News. Uji coba ini dilakukan untuk mengetahui keadaan ketika ada komunikasi antara dua telepon, dan di interupsi oleh user lain.

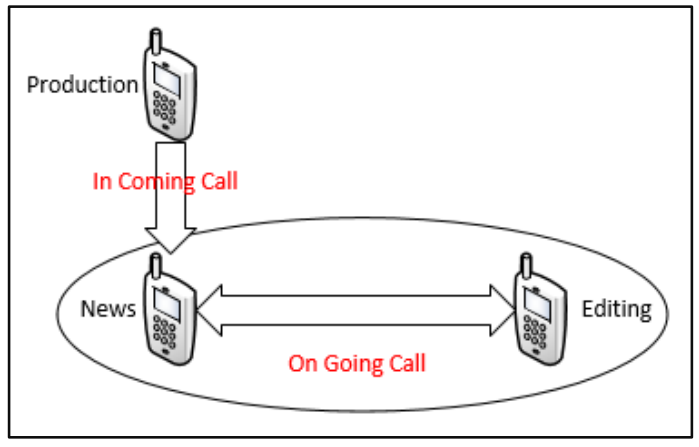

Gambar 5. 2 Kondisi Pertama

Dari kondisi tersebut setelah di uji coba dapat disimpulkan bahwa telepon antara News dan Editing dapat berjalan seperti biasa dan tidak ada gangguan suara dari luar. Tetapi panggilan yang dilakukan oleh user Production yang akan mendapatkan voicemail yang berbunyi "sorry that is not a valid extention". Hal ini terjadi ketika panggilan dari user Production tidak diangkat oleh user News.

\section{B. Kondisi kedua}

Kondisi kedua yaitu melakukan pengujian dengan mengangkat telepon lain yang masuk pada salah satu user ketika sedang terjadi proses dial. Pada pengujian ini akan ada interupsi dari user Production pada proses dial user News dan user Editing. Uji coba ini bertujuan untuk mengetahui apa yang akan terjadi ketika telepon interupsi tersebut diangkat. Dari pengujian yang telah dilakukan maka ketika interupsi dan telepon tersebut diangkat, maka user Production dapat mendengarkan suara dari user News tetapi user News tidak dapat mendengarkan suara dari user Production.

\section{Kondisi tiga}

Kondisi ketiga yaitu ketika 6 user dari masingmasing divisi melakukan panggilan pada waktu yang bersamaan. Pengecekan akan diambil dari dua uji coba. Yaitu pengecekan terhadap bandwidth dan pengecekan terhadap memori ketika panggilan berlangsung. Terlihat seperti gambar dibawah ini:

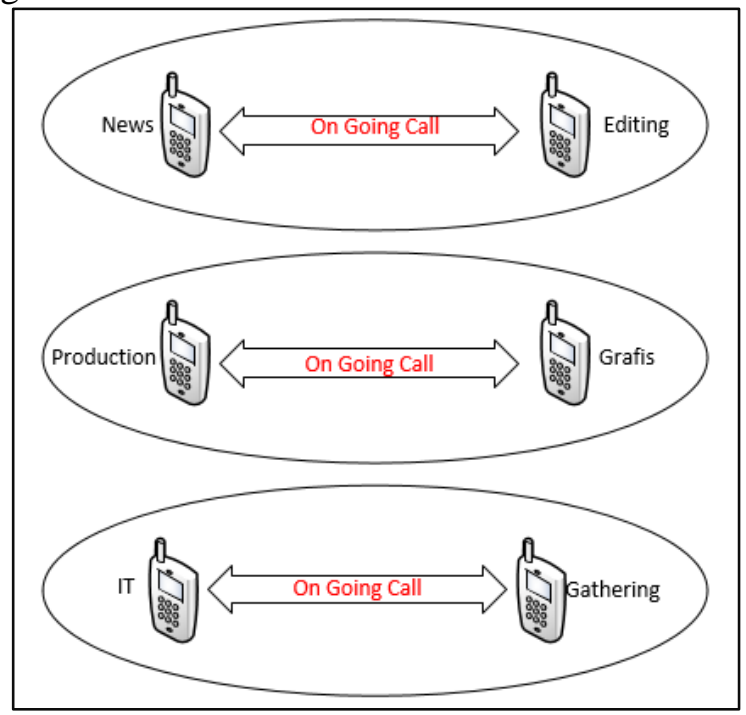

Gambar 5. 3 Kondisi Ketiga

Setelah dilakukan beberapa percobaan maka dibawah ini adalah data yang dihasilkan:

Tabel 5. 1 Hasil Pemakaian Bandwidth

\begin{tabular}{|c|c|c|c|}
\hline Percobaan & RX & TX & Keterangan \\
\hline 0 user & $27.52 \mathrm{KiB}$ & $32.11 \mathrm{KiB}$ & Berhasil \\
\hline 2 user & $39.16 \mathrm{KiB}$ & $41.90 \mathrm{KiB}$ & Berhasil \\
\hline 4 user & $85.97 \mathrm{KiB}$ & $93.44 \mathrm{KiB}$ & Berhasil \\
\hline 6 user & $145.54 \mathrm{KiB}$ & $159.84 \mathrm{KiB}$ & Berhasil \\
\hline
\end{tabular}

Dari beberapa percobaan yang telah dilakukan dapat disimpulkan adanya peningkatan troughput di server VoIP ketika adanya panggilan yang dilakukan dan troughput semakin meningkat ketika banyak user melakukan panggilan di waktu yang bersamaan.

Berikut adalah hasil dari semua percobaan untuk mengetahui pemakaian memori pada proses 
telepon ketika tidak berlangsung dan sedang berlangsung yang telah dilakukan:

Tabel 5. 2 Hasil Pemakaian Memori

\begin{tabular}{|c|c|c|c|c|c|c|}
\hline Percobaan & Total & Free & Used & Buff/cache & Avail & Keterangan \\
\hline 0 user & 7649808 & 7018564 & 278200 & 353044 & 7128664 & Berhasil \\
\hline 2 user & 7649808 & 7017384 & 278452 & 353972 & 7128316 & Berhasil \\
\hline 4 user & 7649808 & 7006536 & 288260 & 355012 & 7118580 & Berhasil \\
\hline 6 user & 7649808 & 6984016 & 301032 & 364760 & 7105624 & Berhasil \\
\hline
\end{tabular}

Table di atas menggambarkan bahwa semakin banyak user yang melakukan panggilan pada waktu yang bersamaan, maka semakin banyak memori yang terpakai. Meskipun banyak memori yang terpakai, tetapi hal tersebut tidak mengganggu jalannya komunikasi pada saat telepon berjalan.

\section{Kesimpulan}

Berdasarkan kegiatan penelitian yang telah dilakukan mengenai Perancangan Prototype VoIP pada Perusahaan XYZ Menggunakan Opensource Asterisk Dan Virtual Machine Engine Google Cloud, di dapat beberapa kesimpulan yaitu:

a. Asterisk merupakan software yang mudah dibuat untuk digunakan dalam sistem VoIP.

b. Penggunaan Google Cloud mempermudah dalam pengecekan maupun pembaruan sistem karena dapat diakses dimana saja.

c. Berdasarkan hasil uji, penggunaan dual CPU cukup untuk digunakan dalam sistem VOIP pada lantai 3 perusahaan XYZ.

\section{Daftar pustaka}

Jamil, Mohammad., Rosihan, Ahmad Fuad. 2016. Buku Ajar Cloud Computing. Yogyakarta: CV Budi Utama

Madiun, Madcoms. 2015. Membangun Sistem Jaringan Komputer untuk Pemula. Yogyakarta: CV ANDI OFFSET

Yani, Ahmad, 2009. VOIP-Nelpon Murah Pake Internet. Jakarta: PT AgroMedia Pustaka

Yunarti, Welaspen, and Rusdianto Roestam.
"Analisis dan Rancang Bangun Jaringan Komunikasi VOIP Dengan Server Briker Pada SMKN 1 Tanjung Jabung Timur." Jurnal Manajemen Sistem Informasi 3.4 (2018): 1272-1281.

Khuluq, H. (2016). Implementasi VOIP (Voice Over Internet Protocol) Server Berbasis Raspberry pi Sebagai Media Komunikasi. Edutic-Scientific Journal of Informatics Education, 3(1).

Risnandar, M., Hendrawan, A. H., Prakosha, B. A., \& Goeritno, A. (2016). Implementasi Voice Over Internet Protocol (VOIP) Berbasis Session Initiation Protocol (SIP) Berbantuan Briker Versi 1.4 Untuk Pengukuran Quality Of Services Pada Jaringan Komputer di Fakultas Teknik UIKA Bogor. Prosiding Semnastek.

Dwiyatno, S., Sulistiyono, S., \& Nugraheni, M. (2019). Layanan Komunikasi Voip Menggunakan Raspberry Pi Dan Raspbx Pada Smk Al-Insan Terpadu. Prosisko: Jurnal Pengembangan Riset dan Observasi Sistem Komputer, 6(2). 